\title{
Care seeking for children with fever/cough or diarrhoea in Nepal: equity trends over the last 15 years
}

\author{
MATS MÅLQVIST ${ }^{1}, \mathrm{CHAHANA} \mathrm{SINGH}^{2} \&$ ASHISH KC ${ }^{1,2}$ \\ ${ }^{1}$ International Maternal and Child Health, Department of Women's and Children's Health, Uppsala University, Uppsala, \\ Sweden, and ${ }^{2}$ UN Health Section, UNICEF Nepal Country Office, Pulchowk, Nepal
}

\begin{abstract}
Aims: Childhood illnesses such as diarrhoea and pneumonia remain major contributors to child mortality globally and need to be continually targeted in pursuit of universal health coverage. This study analyses time trends in the prevalence of fever/ cough and diarrhoea in Nepal and applies an equity lens in order to identify disadvantaged groups. Methods: Data from the Nepal Demographic Health Surveys of 2001, 2006, and 2011, together with data from the most recent Multiple Indicator Cluster Survey of 2014 performed in Nepal, were utilized for analysis. Results: Analyses revealed improvements (lower prevalence) of diarrhoea and fever/cough in children under five in Nepal over the last 15 years, with an equitable distribution of symptoms over socio-economic determinants. There was, however, a marked and maintained inequity in care seeking for these symptoms, with less educated mothers and those from poor households being only approximately half as likely to seek care for their children. Conclusions: Results highlight the persisting need for targeting care-seeking and societal barriers to treatment in order to achieve universal health access.
\end{abstract}

Key Words: Childhood illness, Nepal, equity, diarrhoea, fever, cough, care seeking

\section{Introduction}

Despite recent improvements in global child survival there is still a long way to go before all preventable child deaths are averted [1]. Globally, most of the deaths of children under the age of five are due to a limited number of causes, with pneumonia and diarrhoea as the main killers [2]. This is despite the fact that the timely recognition of danger signs, with appropriate care seeking, and the administration of simple drugs such as oral antibiotics, oral rehydration solutions (ORS), and zinc could prevent most of these deaths [3]. Efforts have been made to implement this knowledge, which has contributed to the rapid improvements in child survival. Even if the gains have favoured the more disadvantaged, with a decreasing inequity in child illness and greater survival as a result [4], there are still reasons to raise concerns about the unequally distributed burden of childhood disease and deaths [5].

In light of the new Sustainable Development Goal (SDG) agenda, it is not only important to continue to promote the implementation of antibiotics, ORS, and zinc for small children, but also to assure universal coverage of these interventions [6]. However, pneumonia - and, even more so, diarrhoea - has societal causes, with improper hygiene, poor sanitation, and malnutrition as root causes $[7,8]$. Thus, it is not only the lack of knowledge or accessibility to treatment that pose a challenge to equity since the prevalence of these diseases can be assumed to be skewed in disfavour of the disadvantaged [7].

In Nepal, despite being a low-income country and having slow improvement in per capita income during

Correspondence: Mats Målqvist, International Maternal and Child Health (IMCH), Department of Women's and Children's Health, Uppsala University, SE-751 85 Uppsala, Sweden. E-mail: mats.malqvist@kbh.uu.se

(Accepted 18 November 2016)

(C) Author(s) 2017

Reprints and permissions: sagepub.co.uk/journalsPermissions.nav DOI: $10.1177 / 1403494816685342$

journals.sagepub.com/home/sjp 
the last two decades, significant improvements have been made in child survival, with a $77 \%$ reduction of the country's under-five mortality rate during the Millennium Development Goal (MDG) reporting period, from $158 / 1000$ live births in 1990 to $36 / 1000$ in 2015 [4]. This achievement in reaching the MDG 4 target has largely been attributed to broad coverage and reduction of the equity gap in vaccination against childhood disease [9]. In the last two decades, investments have also been made in developing and strengthening a community-based network of health volunteers all over the country [10]. Local communities selected female community health volunteers (FCHVs) from their community to promote preventive health services as well as refer for care to health facilities [11]. Volunteers promoted immunization services as well as provided treatment to children with suspected pneumonia and diarrhoea [12]. These FCHVs diagnose acute respiratory infections in children and treat with oral antibiotics; they also identify cases of diarrhoea in the community and provide ORS and zinc [13]. To improve access for services, the community-based program called CommunityBased Integrated Management of Childhood Illness (CB-IMCI) entrusted the FCHVs with the treatment of sick children at the household and community level [14]. The CB-IMCI had three major strategic approaches of implementation: (1) training the health workers and FCHVs in the case-based management of diarrhoea and pneumonia; (2) community mobilization of a community-based network to improve care seeking from care givers; and (3) strengthening the supply of commodities such as oral antibiotics, zinc, and ORS $[15,16]$. The program started in 1998 and was scaled up nationwide in 2009 [17]. The objective of this public health effort was to access the hard-to-reach and it was expected that this intervention would reduce inequity in child health [16].

In Nepal, health care-seeking behaviour for childhood illnesses is known to be associated with social factors such as the caregiver's level of education, family income [18], and the child's gender [19]. This is further compounded by the existing traditional beliefs and practices that not only delay care seeking but also push the sick child towards severity.

Investigating changes in health equity over time adds another dimension to the efforts to reduce child mortality. The importance of not only achieving improvements in overall survival but making survival less unjust has been highlighted in recent years. Furthermore, there is growing evidence of more people opting towards the private sector, raising concerns about the quality of some of these services provided by public institutions. It is evident that
Nepal has made huge strides in the struggle to improve the health of children. The aims of this study are, therefore, to assess changes in equity for the prevalence of fever/cough and diarrhoea and care seeking in connection to those symptoms of illness over the past 15 years.

\section{Method}

Sample and variables of interest

Data from the Nepal Demographic Health Surveys (DHS) of 2001, 2006, and 2011, together with data from the most recent Nepalese Multiple Indicator Cluster Survey (MICS5) of 2014, were utilized for analysis. Sampling procedures have been described elsewhere and can be considered representative for Nepal at large [20-23]. The main outcome variables were whether parents reported that their child had diarrhoea or fever/cough within the two weeks prior to the survey. In addition, seeking care for the symptoms reported was included as an outcome variable of interest. In order to analyse equity gaps in relation to these main outcome variables, all available structural determinants were included as independent variables. The theoretical framework set up by the Commission of Structural Determinants of Health $(\mathrm{CSDH})$ guided the analysis [24]. The CSDH framework emphasizes social position, as decided by a number of structural determinants, as the main driver of inequities in health. We thus included wealth status, education level of mother, ethnicity of household head (not available in MICS5), religious belonging (not available in MICS5), and gender of child in the analysis. We deviated, however, from the CSDH framework by including place of residence as a structural determinant. In the CSDH framework, living area is considered a proximal determinant; but given the inaccessible geography of Nepal's mountainous regions, as well as recent research focus on the urbanrural divide, we also incorporated these variables as potential drivers of inequity.

Wealth, or economic status, was defined through a pre-set wealth index based on assets and calculated by Principal Components Analysis as defined in the respective survey methodologies [25]. Mother's education level was defined as either the mother being illiterate or literate, or whether the mother has completed primary education or not. There are multiple ethnic groups in Nepal and the caste system is interlinked with ethnicity. A dichotomization between advantaged and disadvantaged groups was made, with Dalits, lower-caste Janajatis, non-dalit Terai caste, and religious minorities classified as disadvantaged, and upper-caste and better-off Janajatis being 
Table I. Background characteristics.

\begin{tabular}{lcccc}
\hline & $\begin{array}{l}\text { DHS 2001 } \\
n=6978\end{array}$ & $\begin{array}{l}\text { DHS 2006 } \\
n=5545\end{array}$ & $\begin{array}{l}\text { DHS 2011 } \\
n=5306\end{array}$ & $\begin{array}{l}\text { MICS 2014 } \\
n=5349\end{array}$ \\
\hline $\begin{array}{l}\text { Mean age of child (years) } \\
\text { Mothers completed }\end{array}$ & 2.01 & 2.06 & 2.03 & 2.06 \\
secondary school or higher & $244(3.5 \%)$ & $345(6.2 \%)$ & $729(13.7 \%)$ & $1098(20.5 \%)$ \\
Illiterate mothers & & & & $2104(39.7 \%)$ \\
Hindu families & $4734(67.8 \%)$ & $2910(52.5 \%)$ & $4531(85.4 \%)$ & $2396(44.8 \%)$ \\
Disadvantaged caste/ethnicity & $5829(83.5 \%)$ & $4706(84.9 \%)$ & $3158(59.7 \%)$ & N/A \\
Urban residents & $4642(66.6 \%)$ & $3499(64.0 \%)$ & $1091(20.6 \%)$ & $907(17.0 \%)$ \\
Living in mountainous area & $449(6.4 \%)$ & $677(12.2 \%)$ & $1020(19.2 \%)$ & $1577(29.5 \%)$ \\
Gender ratio (boys:girls) & $535(7.7 \%)$ & $483(8.7 \%)$ & 1.08 & 1.10 \\
\hline
\end{tabular}

classified as advantaged groups. In addition, a dichotomization of Hindu and non-Hindu was made.

\section{Data analysis}

The prevalence of diarrhoea and fever/cough in children as defined by the respective survey was calculated and divided by the structural determinants described above. The Chi-square test was used to detect group differences and a $p$-value of $<0.05$ was considered significant.

A multivariable logistic regression analysis was then applied. Even if inequity in health outcomes can be driven by all structural determinants, we chose to keep a focus on wealth status and the mother's education level, since these variables are mostly used to measure inequity in health outcomes. Thus, belonging to the lowest wealth quintile and the mother being illiterate were variables included in all regression models, together with the variables showing a significant difference in the previous analysis using Chi-square tests. Adjusted odds ratios (AdjORs) and 95\% confidence intervals (CIs) were calculated.

A subset analysis of children who reportedly had had diarrhoea or fever/cough in the last two weeks was performed using multivariable logistic regression with care seeking as the dependent variable, classified into whether care was sought for the child or not. In this multivariable analysis, all structural determinants available in the respective surveys were included.

\section{Results}

More than 5000 children were included in each of the surveys (Table I), with the largest sample size in DHS $2001(n=6978)$. Overall, there was a trend towards higher education for mothers over the study period, with an increasing literacy rate from $32.2 \%$ in 2001 to $55.2 \%$ in 2014 , and a greater share of mothers having completed at least secondary education from $3.5 \%$ in 2001 to $20.5 \%$ in 2014 . There is also a clear urbanization trend with a threefold increase in the proportion of families living in urban areas over the study period. Contrary to this trend, it should also be noted that there is a considerably larger proportion of families living in mountainous areas in the MICS5 sample compared to the DHS samples, which might be due to different sample procedures in the survey methodologies. Over time, we can also see an increasing sex ratio between boys and girls in the data material.

Prevalence rates - total and classified by structural determinants - of diarrhoea and fever/cough during the two weeks prior to data acquisition are displayed in Table II. It is notable how the prevalence of both diarrhoea and fever/cough in children dropped by more than 40\% between DHS 2001 and DHS 2006 ( $p<$ 0.01 ) and how the prevalence since then has remained steady - around $20 \%$ for fever/cough and a little more than $10 \%$ for diarrhoea. When classifying prevalence by structural determinants, many group comparisons result in significant differences. There is a general trend to a more equitable distribution over the structural determinants for fever/cough prevalence; whereas, for diarrhoea, there is a pattern of maintained inequity with all structural determinants except gender, showing significant discrepancies between the most disadvantaged and the advantaged.

The multivariable regression analysis indicates a rather equitable distribution of the risk for diarrhoea and fever/cough over wealth and literacy status, with only minor discrepancies between the different surveys. The only result that stands out is the risk for diarrhoea, which in MICS5 data from 2014 displays an increased risk for the poorest segment (AdjOR 1.28, CI 95\% 1.07-1.54) as well as for children of illiterate mothers (AdjOR 1.23, CI 95\% 1.04-1.46). For reported fever/ cough there are no significant differences between groups, neither within nor between surveys (Table III).

Even if there are no great inequities in prevalence of symptoms, a further analysis of care-seeking behaviour for the children with reported symptoms reveals large and persistent inequities, primarily based on wealth status (Figure 1). In 2014, families 


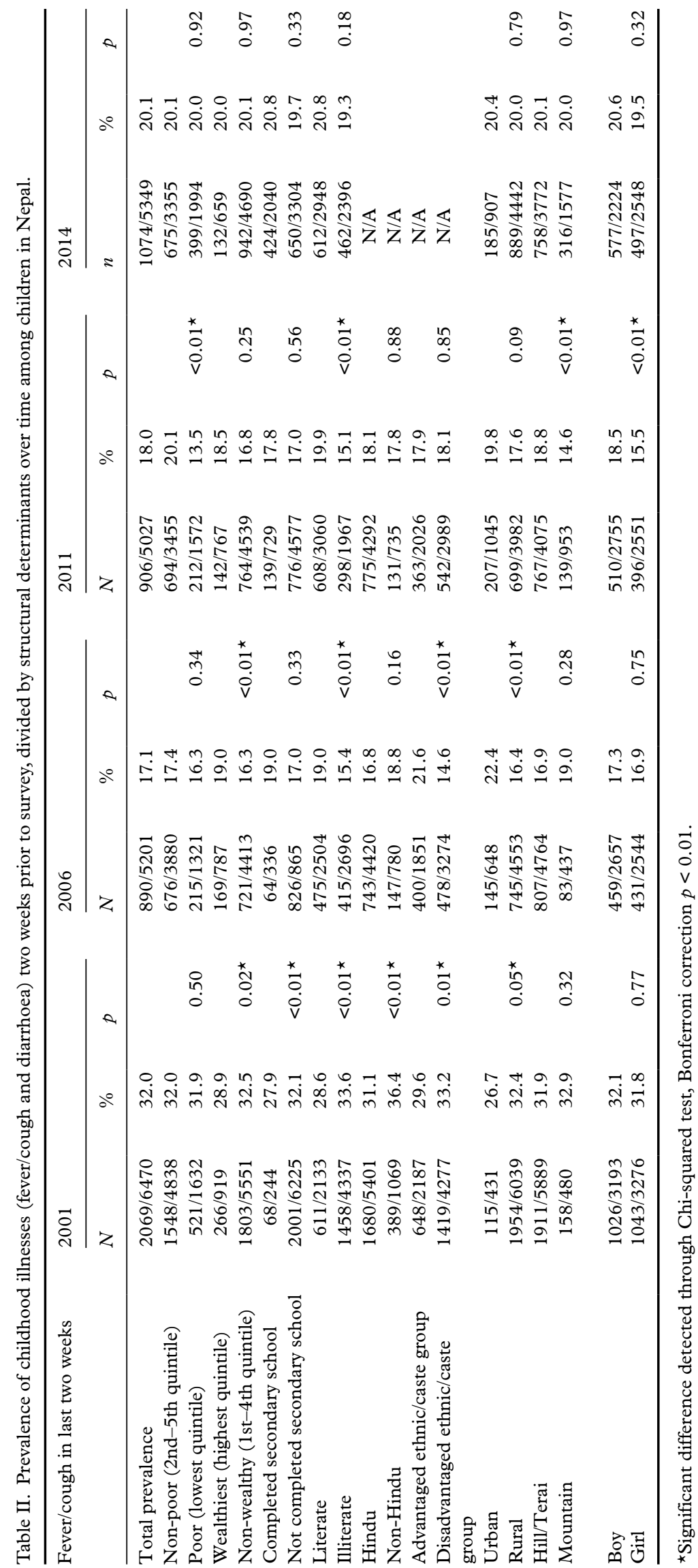


Table III. Multiple logistic regressions for childhood illnesses among children in Nepal. Adjusted Odds Ratios displayed.

\begin{tabular}{|c|c|c|c|c|}
\hline & 2001 & 2006 & 2011 & $2014^{\star}$ \\
\hline \multicolumn{5}{|l|}{ Diarrhoea in last two weeks } \\
\hline Non-poor (2nd-5th quintile) & Ref & Ref & Ref & Ref \\
\hline Poor (lowest quintile) & $1.10(0.96-1.27)^{\mathrm{e}}$ & $1.22(1.00-1.49)^{\mathrm{c}}$ & $0.90(0.75-1.08)^{\mathrm{a}}$ & $1.28(1.07-1.54)^{\star}$ \\
\hline Literate & Ref & Ref & Ref & Ref \\
\hline Illiterate & $1.18(1.03-1.36)^{\mathrm{e} \star}$ & $0.82(0.70-0.98)^{c \star}$ & $1.05(0.88-1.25)^{\mathrm{a}}$ & $1.23(1.04-1.46)^{\star}$ \\
\hline \multicolumn{5}{|l|}{ Fever/cough in last two weeks } \\
\hline Non-poor (2nd-5th quintile) & Ref & Ref & Ref & Ref \\
\hline Poor (lowest quintile) & $0.95(0.84-1.08)^{\mathrm{f}}$ & $0.98(0.82-1.17)^{\mathrm{d}}$ & $0.68(0.57-0.82)^{\mathrm{b} \star}$ & $1.02(0.88-1.20)$ \\
\hline Literate & Ref & Ref & Ref & Ref \\
\hline Illiterate & $1.20(1.06-1.35)^{\mathrm{f} \star}$ & $0.92(0.79-1.08)^{\mathrm{d}}$ & $0.81(0.69-0.95)^{\mathrm{b} \star}$ & $0.91(0.78-1.05)$ \\
\hline
\end{tabular}

aAdjusted for ethnic belonging and sex of child.

bAdjusted for mountain and sex of child.

cAdjusted for mountain, religion, and sex of child.

${ }^{\mathrm{d} A d j u s t e d ~ f o r ~ e t h n i c i t y ~ a n d ~ u r b a n / r u r a l . ~}$

${ }^{\mathrm{e} A d j u s t e d}$ for sex of child, ethnicity, urban/rural, and religion.

${ }^{\mathrm{f} A d j u s t e d ~ f o r ~ e t h n i c i t y, ~ u r b a n / r u r a l, ~ a n d ~ r e l i g i o n . ~}$

${ }^{\star} p>0.05$.

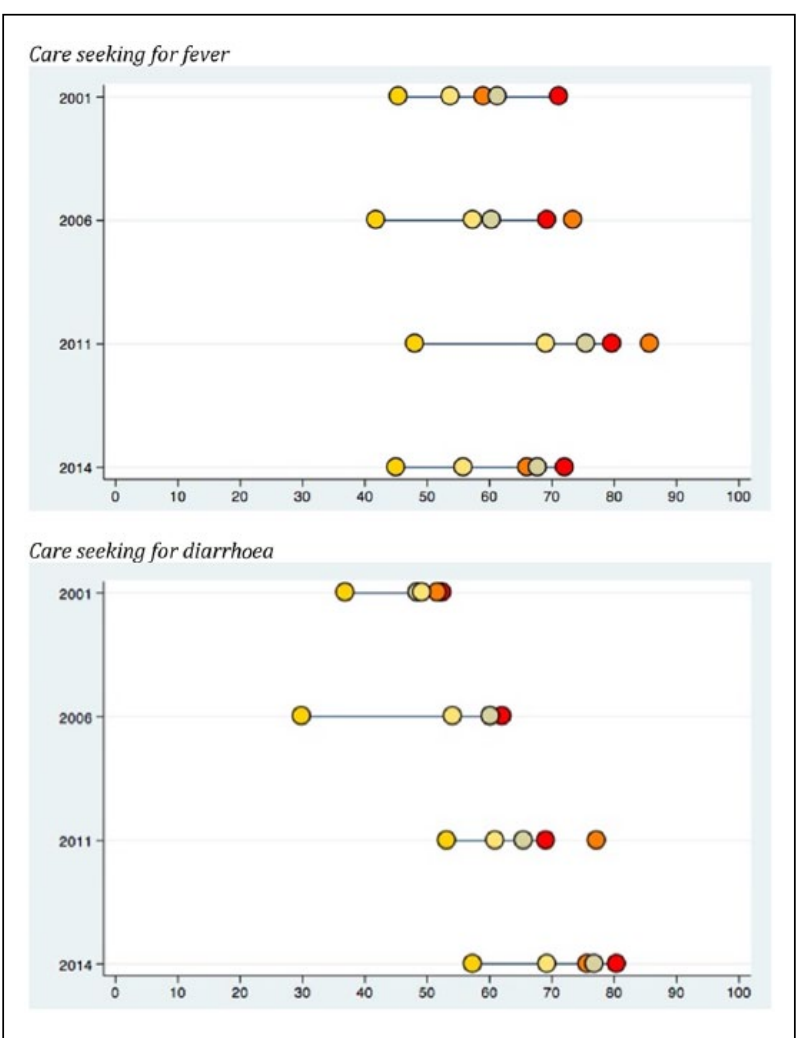

Figure 1. Equiplots displaying percentage of children showing symptoms of fever/cough or diarrhoea in the two weeks preceding survey that care was sought for in Nepal. Wealth quintiles based on DHS 2001, 2006, 2011, and MICS 2014 displayed.

belonging to the poorest quintile were only half as likely to seek care for children showing symptoms of diarrhoea (AdjOR 0.53, CI 95\% 0.37-0.77) or fever/ cough (AdjOR 0.56, CI 95\% 0.44-0.72) compared

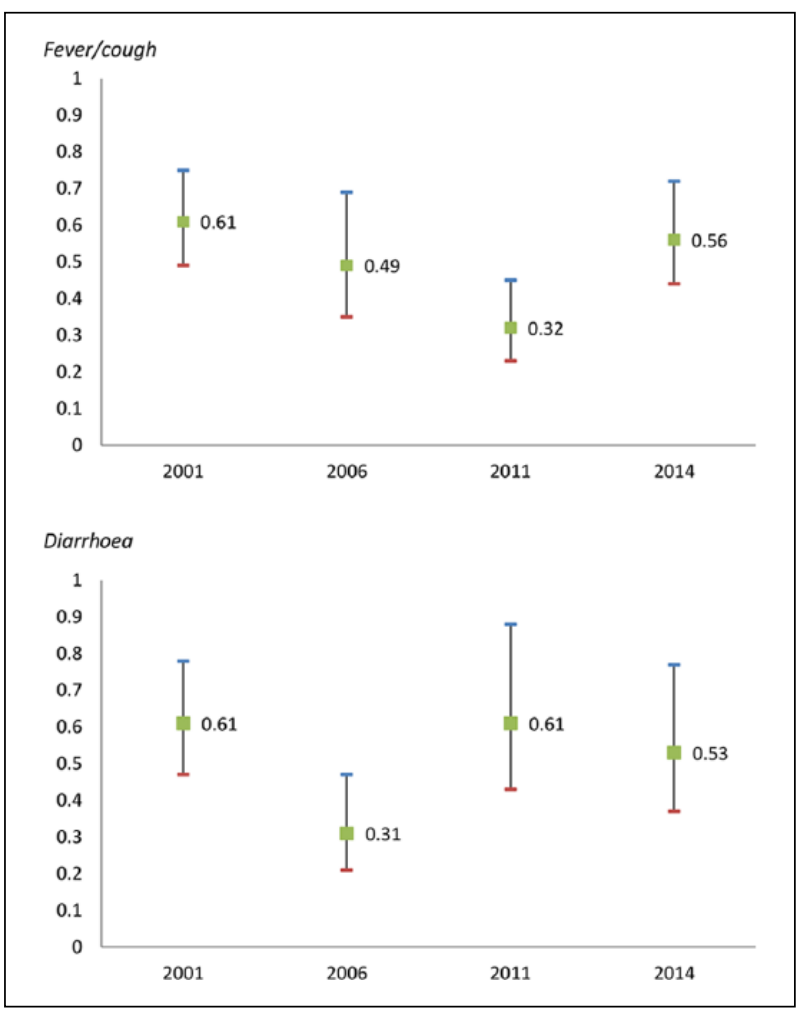

Figure 2. Likelihood of care seeking for child with fever/cough or diarrhoea in the last two weeks for poorest quintile (Ref 2nd-5th quintile. Odds ratios and $95 \%$ confidence intervals are presented. Adjusted for mother's education, living area, sex of child, religious belonging, and ethnicity.

to the better-off families. These differences were also observed in the previous surveys, all with significant results and with overlapping confidence intervals between surveys (Figure 2). 


\section{Discussion}

To summarize the study, three main results can be highlighted. Firstly, there was a large reduction in disease prevalence between the 2001 DHS and the 2006 DHS, and thereafter the prevalence was steady. The dramatic decrease in the prevalence in diarrhoea and fever/cough from 2001 to 2006 can be attributed to a scaling up of the CB-IMCI program during this period. CB-IMCI programs promoted healthy behaviour for early and exclusive breast feeding, improving hygiene, and sanitation for children.

Secondly, there were no major inequities detected in relation to fever/cough symptoms based on the structural determinants, with a trend towards a more equitable distribution, and only minor inequities in symptoms of diarrhoea in children prevailing over the four surveys.

Thirdly, there were large and persisting inequities in care seeking for the noted symptoms, with family wealth being the most predominant structural determinant. The inequity displayed in care seeking could be explained by a multitude of factors, one being the cost of seeking care, as has been shown in studies from around the world [26-28].

The recognition of childhood illness is a prerequisite for both care seeking and adequate treatment. A systematic review, however, found that there is a scarcity of studies on the recognition of childhood illnesses [29], and that the recognition rate overall was low. The lack of inequity in the prevalence of fever/cough and diarrhoea in the survey material might thus be attributed to a reporting error since symptoms were self-reported by caregivers. From an equity perspective, it thus becomes more important to look at the actual care seeking for a perceived illness.

\section{Data sharing statement}

Data was accessed by permission from DHS and MICS. Additional data can be retrieved at: http:// dhsprogram.com/data/ and http://www.childinfo.org

\section{Declaration of conflicting interests}

The author(s) declared no potential conflicts of interest with respect to the research, authorship, and/or publication of this article.

\section{Funding}

The author(s) disclosed receipt of the following financial support for the research, authorship, and/or publication of this article: This work was supported by UNICEF Nepal.

\section{References}

[1] Requejo JH, Bryce J, Barros AJ, et al. Countdown to 2015 and beyond: fulfilling the health agenda for women and children. Lancet 2015;385:466-76.

[2] Young M, Wolfheim C, Marsh DR, et al. World Health Organization/United Nations Children's Fund joint statement on integrated community case management: an equity-focused strategy to improve access to essential treatment services for children. Am F Trop Med Hyg 2012;87:6-10.

[3] Bryce J, Friberg IK, Kraushaar D, et al. LiST as a catalyst in program planning: experiences from Burkina Faso, Ghana and Malawi. Int F Epidemiol 2010;39(Suppl 1):i40-7.

[4] Victora CG, Requejo JH, Barros AJ, et al. Countdown to 2015: a decade of tracking progress for maternal, newborn and child survival. Lancet 2016;387:2049-59.

[5] Gill CJ, Young M, Schroder K, et al. Bottlenecks, barriers, and solutions: results from multicountry consultations focused on reduction of childhood pneumonia and diarrhoea deaths. Lancet 2013;381:1487-98.

[6] Tangcharoensathien V, Mills A and Palu T. Accelerating health equity: the key role of universal health coverage in the Sustainable Development Goals. BMC Medicine 2015;13:101.

[7] Victora CG, Schellenberg JA, Huicho L, et al. Context matters: interpreting impact findings in child survival evaluations. Health Policy Plan 2005;20(Suppl 1):i18-31.

[8] Acharya A, Liu L, Li Q, et al. Estimating the child health equity potential of improved sanitation in Nepal. BMC Public Health 2013;13(Suppl 3):S25.

[9] Ministry of Health and Population (MoHP), Government of Nepal. Nepal Health Sector Programme II: 2010-2015. Kathmandu: MoHP, 2010.

[10] Kc A, Bhandari NA, Pradhan YV, et al. State of maternal, newborn and child health programmes in Nepal: what may a continuum of care model mean for more effective and efficient service delivery? F Nepal Health Res Counc 2011;9:92-100.

[11] Kc NP, Kc A, Sharma N, et al. Community participation and mobilization in community-based maternal, newborn and child health programmes in Nepal. $\mathcal{F}$ Nepal Health Res Counc 2011;9:101-6.

[12] Houston R, Acharya B, Poudel D, et al. Early initiation of community-based programmes in Nepal: a historic reflection. F Nepal Health Res Counc 2012;10:82-7.

[13] Miyaguchi M,Yasuoka J, Poudyal AK, et al. Female community health volunteers service utilization for childhood illness - improving quality of health services only is not enough: a cross-sectional study in mid-western region, Nepal. BMC Health Serv Res 2014;14:383.

[14] Ministry of Health and Population (MoHP), Government of Nepal. CB-IMCI annual report 2006/2007. Kathmandu: MoHP, 2007.

[15] Dawson P, Pradhan Y, Houston R, et al. From research to national expansion: 20 years' experience of communitybased management of childhood pneumonia in Nepal. Bull World Health Organ 2008;86:339-43.

[16] Ministry of Health, Government of Nepal. Communitybased Integrated Management of Childhood Illnesses Programme Nepal. Kathmandu: Department of Health Services, Ministry of Health and Population, 1997.

[17] Department of Health Services and Ministry of Health and Population (MoHP), Government of Nepal. National female community health volunteer program strategy. Kathmandu: MoHP, 2009.

[18] Sreeramareddy CT, Shankar RP, Sreekumaran BV, et al. Care seeking behaviour for childhood illness-a questionnaire survey in western Nepal. BMC Int Health Hum Rights 2006;6:7.

[19] Pokhrel S, Snow R, Dong H, et al. Gender role and child health care utilization in Nepal. Health Policy 2005;74:100-9. 
[20] Central Bureau of Statistics/Government of Nepal and UNICEF. Nepal Multiple Indicator Cluster Study 2014: key findings and tables. Kathmandu, 2015.

[21] Ministry of Health and Population (MoHP), Government of Nepal, New ERA and ICF International Inc. Nepal Demographic and Health Survey 2001. Kathmandu and Calverton, MA: MoHP, New ERA and ICF International, 2002.

[22] Ministry of Health and Population (MoHP), Government of Nepal, New ERA and ICF International Inc. Nepal Demographic and Health Survey 2006. Kathmandu and Calverton, MA: MoHP, New ERA and ICF International, 2007.

[23] Ministry of Health and Population (MoHP) Government of Nepal, New ERA and ICF International Inc. Nepal Demographic and Health Survey 2011. Kathmandu and Calverton, MA: MoHP, New ERA and ICF International, 2012.

[24] CSDH. Closing the gap in a generation: health equity through action on the social determinants of health. Final Report of the
Commission on Social Determinants of Health. Geneva: World Health Organization, 2008.

[25] Ruthstein SO and Johnson K. The DHS wealth index. DHS comparative report no. 6. Calverton, MA: ORC Macro, 2004.

[26] Teerawichitchainan B and Phillips JF. Ethnic differentials in parental health seeking for childhood illness in Vietnam. Soc Sci Med 2008;66:1118-30.

[27] Ustrup M, Ngwira B, Stockman LJ, et al. Potential barriers to healthcare in Malawi for under-five children with cough and fever: a national household survey. $\mathcal{F}$ Health Popul Nutr 2014;32:68-78.

[28] Das SK, Nasrin D, Ahmed S, et al. Health care-seeking behavior for childhood diarrhea in Mirzapur, rural Bangladesh. Am f Trop Med Hyg 2013;89:62-8.

[29] Geldsetzer P,Williams TC, Kirolos A, et al. The recognition of and care seeking behaviour for childhood illness in developing countries: a systematic review. PLoS One 2014;9:e93427. 